\title{
НАЛОГОВО-БЮДЖЕТНАЯ ПОЛИТИКА В АЛЖИРЕ (2000-2016 ГГ.)
}

\author{
(c) 2021 Абдулла Али Аль-Масаид \\ соискатель \\ Казанский (Приволжский) федеральный университет, Россия, Казань \\ E-mail: almasaeed.abdullah@yahoo.com.ph
}

Актуальность исследования заключается в резком колебании мировых цен на нефть в последние годы. В статье на примере Алжира отражен вектор политики государства при высоких и низких ценах на углеводородное сырье. Предметом исследования является экономика Алжира, поскольку в данном африканском государстве ключевую роль в формировании бюджета играет углеводородный сектор. По итогам исследования выявлено, что при стабильно высоких ценах на топливо Алжир принимает экспансионистскую финансовую политику. Обратная ситуация ведет к дефляционной фискальной политике. Исследование имеет практическую значимость, поскольку в нем отражены конкретные шаги государства по приведению экономики в состояние «финансового покоя».

Ключевые слова: бюджетно-налоговая политика, фискальная политика, экономический рост, инфляция, инвестиции, нефтяная зависимость, стратегическое планирование, арабские страны, Алжир.

Государственные расходы в Алжире в последние годы постоянно значительно увеличивались в период с 2000 по 2016 год (1 алжирский динар (DZD) 0,57 российских рублей).

Период с 2000 по 2016 гг., можно разделить на две фазы экономического развития Алжира:

Первая фаза (2000-2009 гг.).

Бюджетная политика в области расходов в этот период претерпела резкие изменения по сравнению с девяностыми годами, в которых была принята политика жесткой экономии, достигаемая дополнительными экономическими реформами. Период начала века ознаменовался возвращением высоких цен на нефть на мировом рынке, что добавило своеобразного финан- сового комфорта. Это время было использовано для оживления экономической деятельности посредством проведения экспансионистской бюджетно-финансовой политики в целях решения острых экономических и социальных проблем, с которыми Алжир столкнулся в 90-е годы.

Государственные расходы в этот период быстро выросли: с 1178,1 млрд. динаров в 2000 году до 1639,2 млрд. динаров в 2003 году. Затем расходы возросли до 2052,0 млрд. динаров в 2005 году, и достигли 4191,0 млрд. динаров в 2008 году, увеличившись на 255\% с 2000 по 2008 годы.

Вторая фаза с (2010-2016 гг.).

В этот период реализовывалась пятилетняя программа развития (2010-2014 гг.), на которую

Таблиц̧а 1. Динамика и виды расходов (2000-2016 годы), млрд. алжирских динаров

\begin{tabular}{|c|c|c|c|c|c|c|}
\hline Год & $\begin{array}{c}\text { Общие } \\
\text { расходы }\end{array}$ & Темп роста, \% & $\begin{array}{c}\text { Текущие } \\
\text { расходы }\end{array}$ & $\begin{array}{c}\text { Их доля в } \\
\text { суммарных } \\
\text { расходах, \% }\end{array}$ & $\begin{array}{c}\text { Инвестицион- } \\
\text { ные расходы }\end{array}$ & $\begin{array}{c}\text { Их доля в } \\
\text { расходах, \% }\end{array}$ \\
\hline 2000 & 1178,1 & ---- & 856,1 & 72,67 & 321,9 & 27,33 \\
\hline 2001 & 1321,0 & 12,13 & 963,6 & 72,95 & 357,3 & 27,05 \\
\hline 2003 & 1639,2 & 5,71 & 1122,7 & 68,49 & 516,5 & 31,51 \\
\hline 2004 & 1888,9 & 15,23 & 1250,8 & 66,22 & 638,0 & 33,78 \\
\hline 2006 & 2453,0 & 19,54 & 1437,8 & 58,62 & 1015,1 & 41,38 \\
\hline 2007 & 3108,6 & 26,73 & 1674,0 & 53,85 & 1434,6 & 46,15 \\
\hline 2009 & 4246,3 & 1,32 & 2300,0 & 54,16 & 1946,3 & 45,84 \\
\hline 2010 & 4466,9 & 5,20 & 2659,0 & 59,53 & 1807,8 & 40,47 \\
\hline 2012 & 7058,2 & 23,15 & 4782,6 & 67,76 & 2275,5 & 32,24 \\
\hline 2013 & 6024,1 & $-14,65$ & 4131,5 & 68,58 & 1892,6 & 31,42 \\
\hline 2015 & 7656,3 & 9,44 & 4617,0 & 60,30 & 3039,3 & 39,70 \\
\hline 2016 & 7297,5 & $-4,69$ & 4585,6 & 62,84 & 2711,9 & 37,16 \\
\hline
\end{tabular}


было выделено 21214 млрд. алжирских динаров (286 млрд. долларов) в рамках продолжения программ, установленных алжирским государством, начатых в начале третьего тысячелетия. Можно отметить, что государственные расходы изменились с 4466,9 млрд. динаров в 2010 году до 7058,2 млрд. динаров в 2012 году, с ростом на $58 \%$, и это связано с расширяющейся фискальной политикой, проводимой государством для реализации пятилетнего плана и перехода к устойчивому развитию. Но этому плану не удалось стать успешным из-за снижения государственных расходов в результате падения мировых цен на нефть.

На приведенной выше диаграмме мы замечаем тенденцию к росту государственных расходов на протяжении всех лет исследования, за исключением 2013 и 2016 годов, в которых наблюдалось их снижение. Также на диаграмме видно доминирование текущих расходов по отношению к инвестиционным расходам на протяжении всего периода исследования.

Динамика государственных доходов, в том числе нефтяных сборов отражена в таблице 2 . Доходы увеличивались с разными темпами, при этом в 2001 и 2009 годах наблюдалось их снижение по сравнению с годом, непосредственно предшествующим ему.

На рисунке 2 можно увидеть повышение как общего дохода, так и общих нефтяных сборов. В дополнение к неналоговым доходам наблюдается непрерывный рост каждого из них. Отмечается также доминирование соотношения нефтяных сборов к государственным доходам за исключением 2015 года и в последующий период, где доля обычных сборов превышала долю нефтяных сборов.

Наблюдая за развитием компонентов финансовой политики в Алжире, можно выделить следующие особенности:

- Зависимость финансовой политики в Алжире от доходов от нефти и ее связь с ценами на нефть, поскольку доходы от нефти составляют более $60 \%$ общих доходов государственного бюджета, что косвенно означает, что государственные расходы связаны с ценами на нефть. Это создает риски, поскольку рынок нефти формируется из вне, и правительство не может финансировать свои расходы в случае обвала цен на нефть;

- В общем бюджете Алжира преобладает характер непрерывного дефицита. Дефицит бюджета стал обычным явлением и сохранялся в течение нескольких лет даже в периоды восстановления доходов. Основными причинами этого дефицита являются непрерывное увеличение государственных расходов;

- Корреляция фискальной политики в Алжире с ценами на нефть, привела к принятию экспансионистской фискальной политики в периоды бума и дефляционной фискальной политики в периоды спада. Таким образом, она усиливает инфляционное давление в периоды бума и продлевает период дефляции в случае спада, в то время как требуется обратное. В период бума правительство должно проводить сдерживающую фискальную политику для поглощения инфляции, а также осуществлять экспансиони-

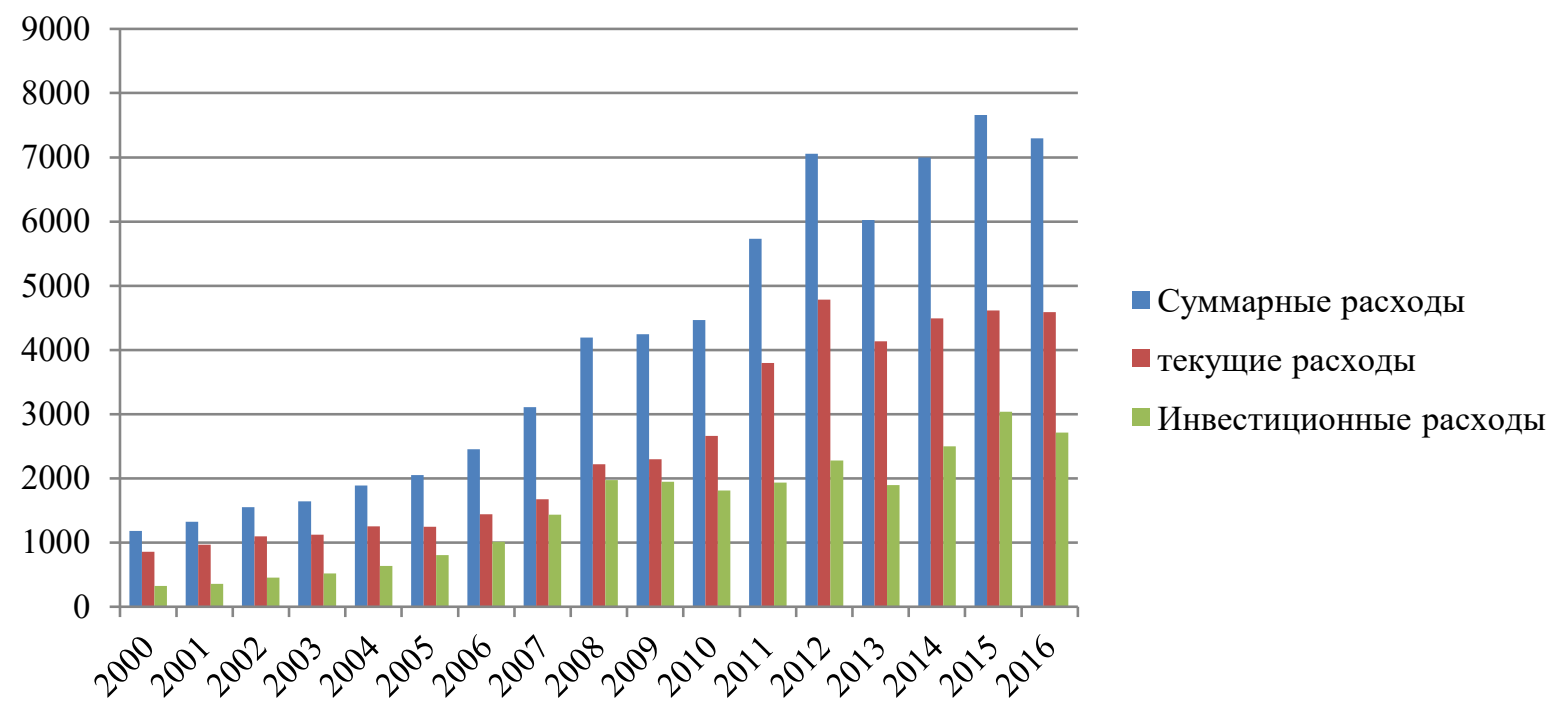

Puc. 1. Динамика расходов и их виды в Алжире с (2000-2016 гг.) 
Таблица 2. Динамика государственных доходов в Алжире (2000-2016 годы), млрд. алжирских динаров

\begin{tabular}{|c|c|c|c|c|c|c|c|c|c|}
\hline 氜 & $\begin{array}{l}\overrightarrow{0} \\
0 \\
0 \\
0 \\
0 \\
0 \\
0 \\
0 \\
\vdots \\
0 \\
0\end{array}$ & 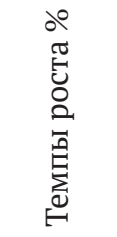 & 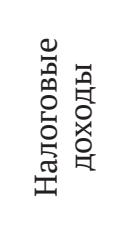 & 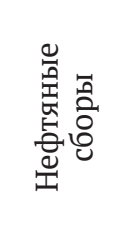 & 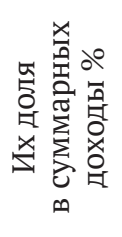 & 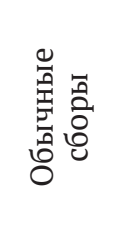 & 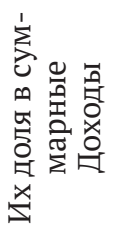 & 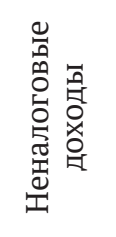 & 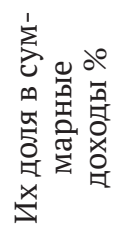 \\
\hline 2000 & 1578,16 & -- & 1522,73 & 1173,23 & 74,34 & 349,5 & 22,15 & 55,42 & 3,51 \\
\hline 2001 & 1505,52 & $-4,60$ & 1354,62 & 956,38 & 63,52 & 398,24 & 26,15 & 150,89 & 10,02 \\
\hline 2002 & 1603,18 & 6,49 & 1425,8 & 942,9 & 58,81 & 482,9 & 30,12 & 177,38 & 11,06 \\
\hline 2003 & 1974,46 & 23,16 & 1809,9 & 1284,97 & 65,08 & 524,93 & 26,59 & 164,56 & 8,33 \\
\hline 2004 & 2229,89 & 12,94 & 2066,11 & 1485,69 & 66,63 & 580,42 & 26,03 & 163,78 & 7,34 \\
\hline 2005 & 3082,82 & 38,25 & 2908,3 & 2267,83 & 73,56 & 640,47 & 20,78 & 174,52 & 5,66 \\
\hline 2006 & 3639,92 & 18,07 & 3434,88 & 2714 & 74,56 & 720,88 & 19,80, & 205,04 & 5,63 \\
\hline 2007 & 3687,9 & 1,32 & 3478,6 & 2711,85 & 73,53 & 766,75 & 20,79 & 209,3 & 5,68 \\
\hline 2008 & 5190,5 & 40,74 & 5053,8 & 4088,6 & 78,77 & 965,2 & 18,60 & 136,7 & 2,63 \\
\hline 2009 & 3676 & $-29,18$ & 3559,3 & 2412,7 & 65,63 & 1146,6 & 31,19 & 116,7 & 3,17 \\
\hline 2010 & 4392,9 & 19,50 & 4203 & 2905 & 66,13 & 1294 & 29,55 & 189,9 & 4,32 \\
\hline 2011 & 5790,1 & 31,81 & 5506,8 & 3979,7 & 68,73 & 1527,1 & 26,37 & 283,3 & 4,89 \\
\hline 2012 & 6339,3 & 9,49 & 6092,9 & 4184,3 & 66,01 & 1908,6 & 30,11 & 246,4 & 3,89 \\
\hline 2013 & 5957,5 & $-6,02$ & 5709,1 & 3678,1 & 61,74 & 2031 & 34,09 & 248,4 & 4,17 \\
\hline 2014 & 5738,4 & $-3,68$ & 5479,8 & 3388,4 & 59,05 & 2091,4 & 36,45 & 258,6 & 4,51 \\
\hline 2015 & 5103,1 & $-11,07$ & 4728,2 & 2373,5 & 46,51 & 2354,7 & 46,14 & 374,9 & 7,35 \\
\hline 2016 & 5042,2 & $-1,19$ & 4204 & 1781,1 & 35,32 & 2422,9 & 48,05 & 838,2 & 16,62 \\
\hline
\end{tabular}

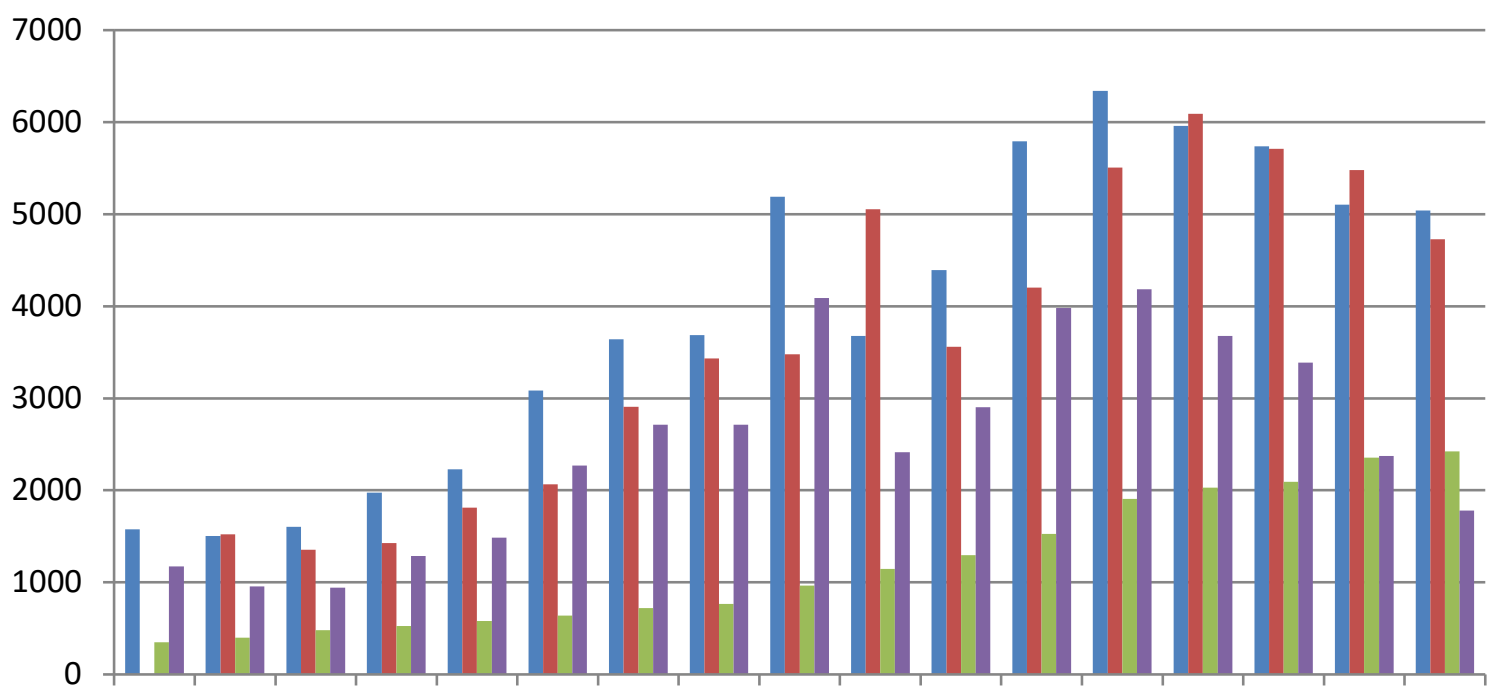

20002001200220032004200520062007200820092010201120122013201420152016

побщие доходы доходы обычные доходы доходы от нефти

Puc. 2. Динамика государственных доходов в Алжире за период 2000-2016 гг. 
стскую фискальную политику в периоды спада для оживления спроса и выхода из дефляции. Это означает, что финансовая политика в Алжире утратила свою роль в борьбе с инфляцией и спадом.

Чтобы изучить темпы экономического роста в Алжире, необходимо проанализировать несколько показателей, представленных в номинальном и реальном ВВП, а также изучить динамику темпов роста ВВП на душу населения. На рисунке 3 отражено развитие этих показателей в течение периода исследования.

Из диаграммы можно отметить, что темпы экономического роста в Алжире в период 20002016 гг. характеризовались резкими колебаниями, и это связано с тем, что на экономический рост в Алжире повлияли колебания цен на нефть. Диаграмма показывает разрыв между темпами роста в текущих и постоянных ценах. Этот разрыв увеличился в период с 2004 по 2012 год в результате высоких темпов инфляции, а через год этот разрыв уменьшился. Это свидетельствует о снижении темпов инфляции в результате реализации программ экономических реформ, проведенных под патронатом Международного валютного фонда. В 2001 году инфляция приблизилась к 30\%. Этот показатель также достиг отрицательного значения в 2009 году - минус 9,74\% в результате мирового финансового кризиса 2008 года, который повлиял на мировой спрос на энергию.

Таким образом, Алжир принимал экспансионистскую финансовую политику особенно во времена профицита бюджета путем увеличе- ния государственных расходов, финансирования проектов и программ развития. Различным группам населения предоставлялись налоговые льготы. Несмотря на прогресс, достигнутый в поддержке инфраструктуры, развитии некоторых секторов и повышении темпов роста, Алжиру не удалось добиться экономической диверсификации. Снижения зависимости от нефти не произошло, поскольку доходы нефтяного сектора по-прежнему составляют значительную долю общих доходов, ВВП и экспорта. Следовательно, их зависимость от единственного источника дохода является одним из самых больших дисбалансов, угрожающих их экономике.

Наблюдая за развитием экономического роста в Алжире, становится ясно, что темпы роста колеблются из года в год, что указывает на то, что на него влияют внешние факторы. В Алжире наблюдались низкие и отрицательные темпы роста в девяностые годы, а в 2000 году и позже темпы роста значительно улучшились, и рост достиг наивысших показателей в этот период.

Мировой финансовый кризис 2008 года оказал негативное влияние на экономику Алжира в результате снижения мирового спроса на углеводород. Этот кризис стал предупреждением для многих сырьевых стран о необходимости пересмотреть проводимую политику и тщательно обдумать поиск эффективных решений для снижения зависимости от нефтяных доходов. Затем эти страны вскоре стали свидетелями еще одного кризиса, представленного резким падением цен на нефть в конце 2014 года. Некоторые из этих стран по сей день страдают от их последствий.

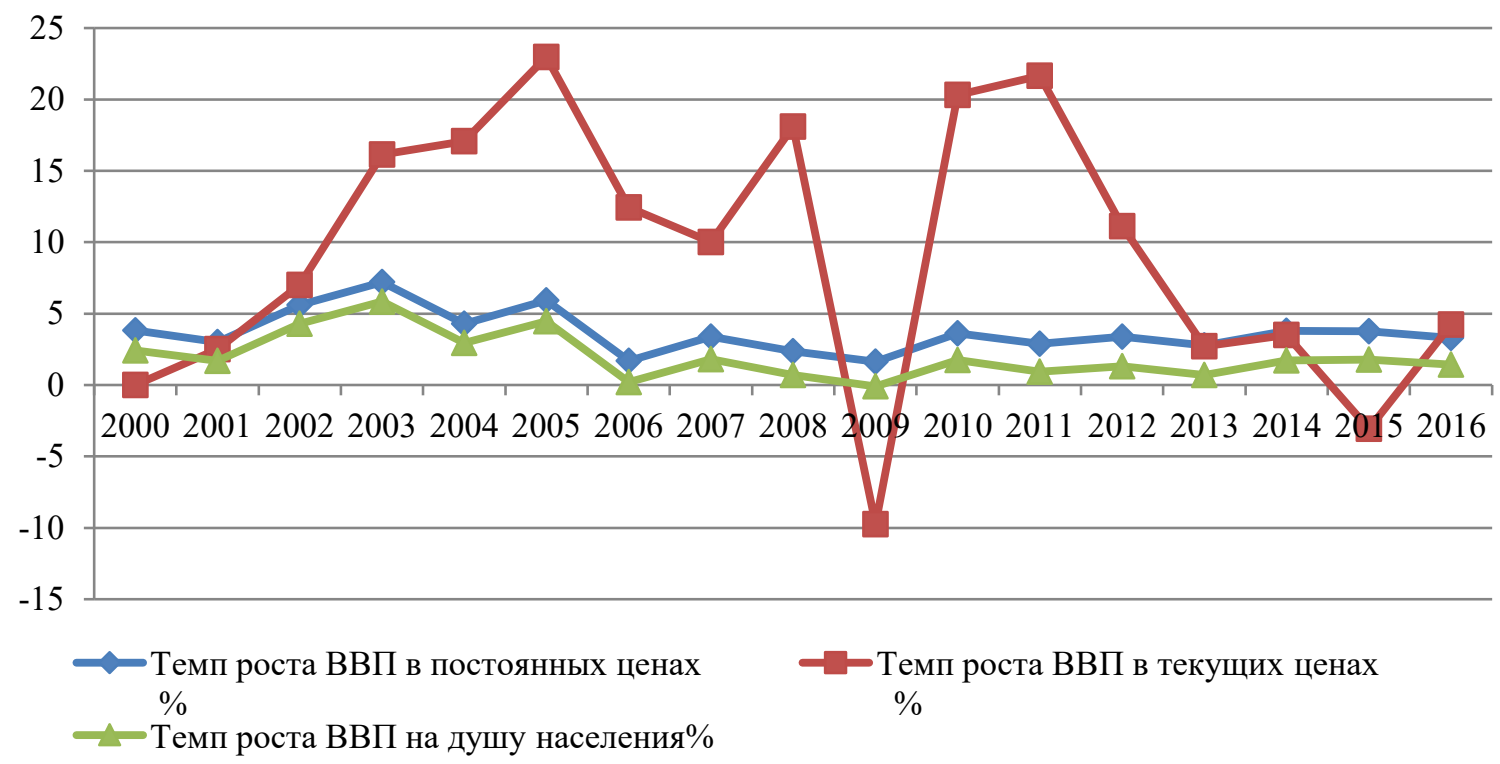

Puc. 3. Изменение темпов экономического роста в Алжире в период 2000-2016 г. 


\section{Библиографический список}

1. Исаева Э.В., Аюпов А. А. Роль финансово устойчивых предприятий в развитии городского округа // Экономика: вчера. сегодня. завтра.-2016. - № 8.- С. 121-130.

2. Сабитова Н. М. Финансовые риски и финансовая деятельность публично-правовых образований // Финансы и кредит. - 2018.- № 3.- С. 565-578.

3. Сабитова Н.М., Шавалеева Ч. М. Нефтегазовый комплекс и риски бюджетной системы Российской Федерации // Нефтяное хозяйство. - 2018. - № 4.- С. 12-15.

4. Сафиуллин Л.Н., БулатоваЭ.И., Хадиуллин Р.И., Шайдуллин Р.Н. Зависимость социально-экономических показателей Республики Татарстан от динамики объемов добычи нефти в регионе // Казанский экономический вестник. - 2020.- № 5.- С. 39-49.

5. Fakhrutdinova E., Severyanov O., Shigabutdinov A., Fakhrutdinov R. The Crisis of 1998 in Russia: political intervention and its implications// Life Science Journal. 2014. T. 11. № 6s. C. 442-447.

6. Fawzia K, The Role of Financial Policy in Stability and Economic Growth in Developing Countries in Light of Current International Transformations: A Case Study of Algeria.- University, Biskra, 2004.-115 p.

7. Kebour N. The Impact of Financial Policy on Economic Growth Algeria as a Model, 1994-2004.- Farhat Abbas University, Setif, Algeria, 2008.- 103 p.

8. Massoud D, Financial Policy and its Role in Achieving Economic Balance: A Case Study of Algeria (1990-2004).Dissertated Dissertation, University of Algiers, 2005.-131 p.

9. Rahim S.A., Batahir S. The Effectiveness of Financial Policy in Algeria: An Analytical Approach // Journal of Development and Economic Policies. - 2010.- Volume 12, Issue 1. - Pp. 37-39.

10. Rahim S.A., Mohamed B.B., Mohamed S.S. The Macroeconomic Impacts of Financial Policy shokes in Algeria: An Empirical Study. - University of Abu Bakr Belqayd, 2007.- 213 p. 